\title{
Effect of Ankle Weight during Gait Training on Dorsiflexors Strength in Hemiparetic Children
}

\author{
HEBA I. AHMED, M.Sc.*; EL-NEGMY E.H, Ph.D.*; KHALED A. OLAMA, Ph.D.* and \\ AMINA S. HENDAWY, M.D.** \\ The Departments of Physical Therapy for Pediatrics, Faculty of Physical Therapy* and Neuropediatrics, Faculty of Medicine**, \\ Cairo University
}

\begin{abstract}
Background: Affected side toe walking is a common problem in hemiparetic cerebral palsy children, that may occur due to spasticity of planter flexors muscles and inhibition of anterior tibial muscles, walking with equines foot lead to abnormal gait pattern, frequent falling down, pain at the metatarsal heads and compensatory reaction that affects hip and trunk and may cause contracture of calf muscle which may need surgery. Using ankle weight during gait training may be an effective treatment tool in hemiparetic children.
\end{abstract}

Aim of Study: The current study was conducted to investigate the effect of using ankle weight during gait training in hemiparetic children.

Subjects and Methods: Thirty hemiparetic children participated in this study, their ages range from 3 to 6 years, all subjects were recruited from the outpatient clinic at the Faculty of Physical Therapy, Cairo University. They were assigned randomly in to two group of equal number; Group A control group received a specific physical therapy program and Group B study group received the same specific physical therapy program as in Group A in addition to weight started $1 / 2 \mathrm{~kg}$ placed above ankle of the affected side during gait training. Hand held dynamometer was used to measure ankle dorsiflexors muscle strength and Kinovea software was used to measure dorsiflexion angle during initial foot contact.

Results: There was a significant increase in ankle dorsiflexors muscle strength and a significant decrease of dorsiflexion angle during initial contact in the study group compared to the control group.

Conclusion: Ankle weight during gait training can be an effective treatment tool in improving dorsiflexors muscle strength in hemiparetic children.

Key Words: Cerebral palsy - Gait - Dorsiflexor strength Ankle weight-Hemiparesis.

Correspondence to: Dr. Heba I. Ahmed, The Department of Physical Therapy for Pediatrics, Faculty of Physical Therapy, Cairo University

\section{Introduction}

CEREBRAL palsy is a neuromotor disorder caused by a lesion to immature brain, the most common problem is hypertonia that appear in the antigravity muscle groups at the lower limb, hypertonia is present in hip extensors, adductors, internal rotators, knee extensors, ankle planterflexors and toes flexors [1]

In hemiparetic cerebral palsy, distribution of spasticity affect one side of the body, in hemiparetic children common pattern of gait is toe walking that result from weakness of anterior tibial group muscle and spasticity of planter flexors [2] .

Changes in neural impulse to muscle has been leading to changes in muscle charateristics. Changes in skeletal muscle morphology causes functional changes in muscle power and length leading to muscle shortening [3].

Spasticity and shortening of planter flexors muscle causes inhibition and weakness of anterior tibial muscles leading to equinus foot and toe walking. Toe walking is the most common functional disability in hemiparetic children [4]

Muscle weakness, and not spasticity, is the greatest restrictions in motor function in hemiparetic cerebral palsy children and this has changed the concept from spasticity management towards strength training. There is direct relationship between strength and gross motor function and gait, the greater the strength the higher the level of function [5]. Strength training should be increased gradually in intensity [6]

There are many procedure utilized to improve force production by using certain muscle groups 
at the ideal time during the gait cycle. Considering that changes at the moment of force generation can favor the system's dynamic reorganization and promote alterations in motor behavior, it is suggested that the physical therapy treatments administered to the gait of children must be based on muscle strengthening and aimed at producing hip flexion strength.

Imposition of resistance during the swing phase of gait-by adding load onto the Lower Limb (LL) -results in compensatory motor responses in the gait of healthy babies and adults, and of adults with neurological pathologies [7].

\section{Subjects and Methods}

By using convenient sampling method thirty hemiparetic children participated in this study. Their ages ranged from 3 to 6 years, grade $1 \& 1$ + spasticity according to Modified Asworth scale and level I \& II GMFM the participants were selected from Outpatient Clinic of Faculty of Physical Therapy Cairo University all patient with visual and auditory problems, fixed contracture and deformity and patient with previous surgical intervention were excluded from the study, the study conducted 3 months from 30 of July to 30 of October 2018. The patients were Quasi randomized into two equal groups (15 patients each):

Control group: Patients received selected physical therapy program conducted for 12 weeks at 3 times/week basis.

Study group: Patients received the same physical therapy program received by patient in the Group $A$ in addition to ankle weight during gait training for 15 to 30 minutes.

\section{Equipment used:}

Measurement tools:

1-For evaluation of spasticity for subject selection: Modified Ashworth scale is a 6-point scale. Scores range from 0 to 4,0 score mean normal muscle tone grade $1 \& 1+$ mean mild hypertonia grade 2 mean moderate hypertonia grade 3 and 4 represent sever spasticity, we included in this study patients with spasticity grade 1 and $1+$.

The test was performed 3 repitition full joint range of motion slowly then 3 repitition fast It is easy and time saving scale that clinically measures spasticity [8].

2- For evaluation of muscle strength: Hand held dynamometer (Lafayette).
The new Lafayette Manual Muscle Testing (MMT) System is an ergonomic hand-held device for objectively quantifying muscle strength.

The test was performed with the clinician applying force to the limb of a patient. The clinician objective of the test is to overcome or "break" the patient's muscle resistance. The MMT system records the peak force and the time required to achieve the "make" providing reliable, accurate, and stable muscle strength readings that conform to most manual muscle testing protocols [9] .

3- For evaluation of gait pattern:Kinovea software: It is a free 2D motion analysis software that enables the establishment of kinematics parameters of gait. It measures accurately at distances up to $5 \mathrm{~m}$ from the object and at an angle range of $90^{\circ}-45$ [10].

Therapeutic tools:

1- Ankle weight: Using different weight $1 / 2 \mathrm{~kg}$, $1 \mathrm{~kg}, 2 \mathrm{~kg}$ weigh.

2- Wedge.

3- Blance board.

4- Stepper.

5- Balance beam.

6- Treadmill.

7- Therapeutic ball.

\section{Procedure:}

Study design: Quasiexperimental design Session was continued for 1 hour for all groups in the form of specific program based on each child evaluation.

\section{The program included:}

1- Neurodevelopmental Technique (NDT): It is effective in improving measures of motor performance in children with $\mathrm{CP}$, especially in gross motor ability, postural control and stability [11]

The aim of treatment was to modulate muscle tone and improve postural alignment by specific handling techniques and then to improve active participation of functional skill [12].

Neurodevelopmental techniques exercises included:

- Quadruped positioning.

- Pelvic control facilitation techniques.

2- Active ROM exercises:

- For upper and lower limb on the affected side, squat to stand, back and abdominal muscle strengthening. 
- Ball exercises.

3- Stretching exercises: For hip flexors, knee flexors, calf muscles in lower limb for elbow flexors, pronators and wrist, fingers flexors.

- Strengthening exercises applied for the lower extremity.

\section{3- Balance training.}

- On balance board standing.

- Single limb stand on affected side.

- Vestibular exercise.

\section{Gait training:}

Both group received the same gait training except that in the study group, gait training was performed by the use of ankle weight around ankle of affected side, starting by half kg-the gradually increased every 2 weeks up to $2 \mathrm{~kg}$.

\section{Gait training included:}

- Mechanical exercise using stepper.

- Exercises on the balance board with or without obstacles.

- Balance beam-exercises.

- Treadmill training with increase inclination gradually forward and back ward.

- Stair climbing.

5- Jumping in and out place.

\section{Statistical analysis:}

Descriptive statistics. And unpaired $t$-test were conducted for comparison of subject characteristics (mean age) between both groups. Chi-squared test was used for comparison of sex, spasticity grades and GMFCS distribution between groups. Levene's test for homogeneity of variances was conducted to ensure the homogeneity between groups. Normal distribution of data was checked using the ShapiroWilk test. Paired $t$-test was conducted for comparison between pre and post-treatment in each group. The level of significance for all statistical tests was set at $p<0.05$. All statistical analysis was conducted through the Statistical Package for Social Studies (SPSS) Version 22 for windows (IBM SPSS, Chicago, IL, USA).

\section{Results}

\section{Subject characteristics:}

Table (1) showed the mean \pm SD age of the control and study groups. There was no significant difference between both groups in the mean age $(p=0.05)$. There was also no significant difference in sex, spasticity grades and GMFCS distribution between groups $(p>0.05)$.

Effect of treatment on dorsiflexors muscle force and dorsiflexion angle:

- Within group comparison: There was no significant difference in dorsiflexors muscle force and dorsiflexion angle between pre and post treatment in the control group $(p>0.05)$.

There was a significant increase in dorsiflexors muscle force and a significant decrease in dorsiflexion angle post-treatment in the study group compared with that pre-treatment $(p>0.001)$.

- Between groups comparison: There was no significant difference in dorsiflexors muscle force and dorsiflexion angle between the two groups pre-treatment $(p>0.05)$. Comparison between the control and study groups post-treatment revealed a significant increase in dorsiflexors muscle force and significant decrease in dorsiflexion angle of the study group compared with that of the control group $(p>0.05)$.

Table (1): Comparison of subject characteristics between control and study groups.

\begin{tabular}{|c|c|c|c|c|}
\hline & $\begin{array}{c}\text { Control group } \\
\text { Mean } \pm \text { SD }\end{array}$ & $\begin{array}{l}\text { Study group } \\
\text { Mean } \pm \text { SD }\end{array}$ & $\begin{array}{c}t- \\
\text { value }\end{array}$ & $\begin{array}{c}p- \\
\text { valuee }\end{array}$ \\
\hline Age (years) & $4.8 \pm 1.14$ & $5.06 \pm 1.03$ & -0.666 & 0.5 \\
\hline $\begin{array}{l}\text { Sex: } \\
\text { Girls } \\
\text { Boys }\end{array}$ & $\begin{array}{l}5(33 \%) \\
10(67 \%)\end{array}$ & $\begin{array}{l}7(47 \%) \\
8(53 \%)\end{array}$ & $\begin{array}{l}\left(\chi^{2} \equiv\right. \\
0.55)\end{array}$ & 0.45 \\
\hline $\begin{array}{l}\text { Spasticity grade: } \\
\text { Grade I } \\
\text { Grade I+ }\end{array}$ & $\begin{array}{l}9(60 \%) \\
6(40 \%)\end{array}$ & $\begin{array}{l}8(53 \%) \\
7(47 \%)\end{array}$ & $\begin{array}{l}\left(\chi^{2} \equiv\right. \\
0.13)\end{array}$ & 0.71 \\
\hline $\begin{array}{l}\text { GMFCS: } \\
\text { Level I } \\
\text { Level II }\end{array}$ & $\begin{array}{l}7(47 \%) \\
8(53 \%)\end{array}$ & $\begin{array}{l}4(27 \%) \\
11(73 \%))\end{array}$ & $\begin{array}{l}\left(\chi^{2}=\right. \\
1.29)\end{array}$ & 0.25 \\
\hline
\end{tabular}

Table (2): Mean dorsiflexors muscle force and dorsiflexion angle of the control and study groups.

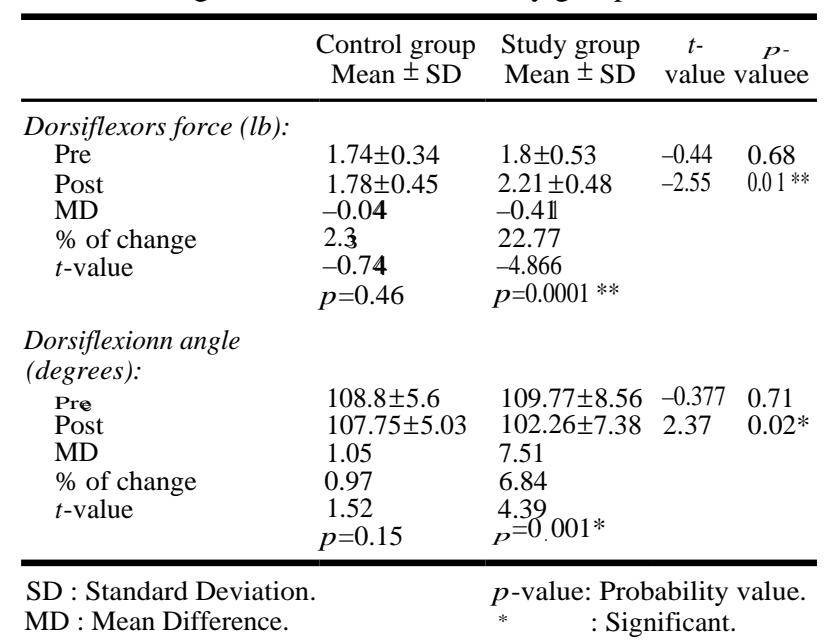




\section{Discussion}

The present study was designed to investigate the effect of ankle weight during gait training on dorsiflexors muscle strength in hemiparetic children. Children with hemiparetic cerebral palsy are often characterized by reduced speed progression, shorter step length, and increased support base. These kinematic alterations result in inefficient gait [13].

Toe-walking is a very common gait abnormality seen in hemiparetic cerebral palsy. Decreased dorsiflexion during the swing phase and lower amplitudes of knee and hip flexion and extension are common [13] beside decreased ability of the flexor plantar muscles to generate propulsion force, these kinematic alterations result in inefficiencies to lift an individual's foot off the surface [14] thus leading to a pattern of "dragging" the Paretic Lower Limb (PLL) during propulsion $[\mathbf{1 4 , 1 5}$. With the purpose of improving the gait efficiency of children with spastic hemiparetic cerebral palsy, techniques of intervention have been suggested and utilized to increase the generation of force by specific muscle groups at the ideal time within the gait cycle. Considering that changes at the moment of force generation can favor the system's dynamic reorganization and promote alterations in motor behavior [14], it is suggested that the physical therapy treatments administered to the gait of children with spastic hemiplegic cerebral palsy must be based on muscle strengthening and aimed at producing hip flexion strength [16]. The literature on the topic describes that the imposition of resistance during the swing phase of gait-by adding load onto the Lower Limb (LL)-results in compensatory motor responses in the gait of healthy babies and adults, and of adults with neurological problems $[17,18]$. Considering that adding load onto the LL overloads flexor muscles during the swing phase, resulting in increased activities and amplitudes of hip and knee flexion during the swing phase of child gait $[\mathbf{1 7 , 2 4 ]}$, it was hypothesized that the presence of such locomotor adjustments would be adequate to improve the propulsion efficiency of the PLL during the swing phase of children with SHCP $[14,25]$.

The results of this study showed that the children with SHCP presented a tendency to modify the joint kinematics in the LL during the swing phase, thus suggesting an ability to display immediate locomotor adaptations in response to the addition of load.
A strong correlation was observed between the amount of load added and the activation of hip flexor muscles [18]

It is suggested that physical therapy treatments for children with SHCP must be directed toward the gain of muscle strength in the hip flexors $[15,25]$ with the purpose of improving gait efficiency.

Adding load to the ankles imposes resistance during the swing phase, which results in a greater activation of the flexor muscles of the LL $[17,24]$ This response can be considered a strategy of neuromotor adaptation mediated by feedback mechanisms that occur due to changes in proprioceptive input during gait with load [21,26], results of another study suggest that the biomechanical behaviour of hip and ankle joints during the swing phase of the gait cycle is linked in patients with hemiparesis. They also suggest that two strategies exist: If sufficient ankle dorsiflexion is present, less hip flexion is required (distal-strategy) whereas if dorsiflexion is reduced, it is compensated for by an increase in peak hip flexion (proximal-strategy) and find that strong positive correlation between hip flexor and ankle dorsiflexor muscle strength.

Proprioceptive Neuromuscular Facilitation (PNF) is a concept of treatment [27] in which the basic philosophy considers that every human, including those with disabilities, has an untapped existing potential [28]. PNF is a method used in clinical practice [29] in order to improve development of neuromuscular system by stimulation of muscle and joint proprioceptors treatment is directed toward the human as a whole and not only as a body segment), based on an untapped existing potential (mobilizing reserves patients), positive approach (reinforcing patient's ability on a physical and psychological level) whose goal is reaching the level of function [30].

Among the PNF's principles, irradiation is a useful aspect for patients with muscle weakness in areas that cannot be directly worked (strengthened) [31]. This principle is based on fact that stimulation of strong and preserved muscle groups produces strong activation of injured and weak muscles, facilitating muscle contraction [32]. So, these weak muscles can develop an increase in the duration and/or intensity by the spread of the response to stimulation or by the synergistic muscle inhibition [33].

Proprioceptive neuromuscular facilitation is one of the main concepts of rehabilitation treatment for patients with neurological injuries, being used 
for several years and spread by known authors such as Kabat, Susan, who defend its efficiency.

Result of other study demonstrate significant increase in hip and knee flexion during swing phase and ankle dorsiflexion in paretic side during treadmill gait training with adding load to ankle increase in hip flexion during swing phase allowed higher paretic foot clearance which may favor the improvement of gait function [34]

\section{Conclusion:}

The result of the study revealed significant increase in dorsiflexors muscle group of paretic side and significant decrease in dorsiflexion angle during initial contact in Group B, in conclusion gait training using ankle weight around affected side starting by half $\mathrm{kg}$ that increased gradually every 2 weeks up to $2 \mathrm{~kg}$ for 15 to 30 minute increasing strength of dorsiflexors muscles of the affected side in hemiparetic children.

\section{References}

1- ROSENBAUM P., PANETH N., LEVITON A., et al.: A report: The definition and classification of cerebral palsy April 2006. Developmental Medicine and Child Neurology, Feb., 49 (109): 8-14, 2007.

2- BLECK E.E.: Orthopedic Management in Cerebral Palsy. Clinics in Developmental Medicine No. 99/100 London: MacKeith Press. 240-51, 1987.

3- NOBLE J.J., FRY N.R., LEWIS A.P., et al.: Lower limb muscle volumes in bilateral spastic cerebral palsy. Brain Dev., 36: 294-300, 2014.

4- FOWLER E.G., STAUDT L.A. and GREENBERG M.B. Lower-extremity selective voluntary motor control in patients with spastic cerebral palsy: Increased distal motor impairment. Dev. Med. Child Neurol., 52: 264-9, 2010.

5- ROSS S.A. and ENGSBERG J.R.: Relation between spasticity and strength in individuals with spastic diplegic cerebral palsy. Dev. Med. Child. Neurol., 44: 148-57, 2002.

6- GUY J.A. and MICHELI L.J.: Strength training for children and adolescents. J. Am. Acad. Orthop. Surg., 9: 2936, 2001.

7- YEN S.C., SCHMIT B.D., LANDRY J.M., et al.: Locomotor adaptation to resistance during treadmill training transfers to overground walking in human SCI. Exp. Brain Res., 216 (3): 473-82, 2012.

8- BOHANNON R.W. and SMITH M.B.: Interrater reliability of a modified Ashworth scale of muscle spasticity. Phys. Ther., 67: 206-7, 1987.

9- DAMIANO D.L., DODD K. and TAYLOR N.F.: Should we be testing and training muscle strength in cerebral palsy? Dev. Med. Child Neurol., 44: 68-72. 10.1017/ S0012162201001682, 2002.

10-PUIG-DIVÍ, PADULLÉS-RIU, BUSQUETS-FACIABEN, et al: Validity and Reliability of the Kinovea Program in
Obtaining Angular and Distance Dimensions, 100042, 2017.

11-TSORLAKIS N., EVAGGELINOU C., GROUIOS G. and TSORBATZOUDIS C.: Effect of intensive neurodevelopmental treatment in gross motor function of children with cerebral palsy. Developmental Medicine \& Child Neurology, 46 (11): 740-5. doi:10.1017/ S001216220 4001276, 2004.

12- KNOX V. and LLOYD-EVANS A.: Therapy in children with cerebral palsy. Developmental and Child Neurology, 44: 447-60, 2002.

13- RODDA J. and GRAHAM H.K.: Classification of gait patterns in spastic hemiplegia and spastic diplegia: A basis for a management algorithm. Eur. J. Neurol., 8 (5): 98-108, 2001

14- FONSECA S.T., HOLT K.G., SALTZMAN E. and FETTERS L.: A dynamical model of locomotion in spastic hemiplegic cerebral palsy: Influence of walking speed. Clin. Biomech. (Bristol, Avon), 16 (9): 793-805, 2001.

15- RIAD J., HAGLUND-AKERLIND Y. and MILLER F.: Power generation in children with spastic hemiplegic cerebral palsy. Gait. Posture, 27 (4): 641-7, 2008.

16-PERRY J.: Análise de Marcha: Marcha Patológica. Barueri: Manole, 2005.

17- LAM T., WOLSTENHOLME C. and YANG J.F.: How do infants adapt to loading of the limb during the swing phase of stepping? J. Neurophysiol., 89 (4): 1920-8, 2003.

18- YEN S.C., SCHMIT B.D., LANDRY J.M., ROTH H. and WU M.: Locomotor adaptation to resistance during treadmill training transfer to overground walking inhuman SCI. Exp. Brain Res., 216 (3): 473-82, 2012.

19- PATCHAY S. and GAHÉRY Y.: Effect of asymmetrical limb loading on earlypostural adjustments associated with gait initiation in young health adults. Gait Posture., 18 (1): $85-94,2003$.

20- HOULDIN A., LUTTIN K. and LAM T.: Locomotor adaptions and aftereffects to resistance during walking in individuals with spinal cord injury. J. Neurophysiol., 106 (1): 247-58, 2011

21- LAM T., WIRZ M. and LÜNENBURGER LAND DIETZ V.: Swing phase resistance enhances flexor muscle activity during treadmill locomotion in incomplete spinal cord injury. Neurorehabil Neural Repair, 22 (5): 438-46, 2008.

22- REGNAUX J.P., PRADON D., ROCHE N., ROBERTSON J., BUSSEL B. and DOBKIN B.: Effects of loading the unaffected limb for one session of locomotor training on laboratory measures of gait in stroke. Clin. Biomech. (Bristo, Avon), 23 (6): 762-8, 2008.

23- KOLLEN B., RIETBERG M., KWAKKEL G. and EMMELOT K.: Effects of overloading of the lower hemiparetic extremity on walking speed in chronic stroke patient: A pilot study. Neuro. Rehabilitation, 14 (3): 15964, 2000.

24- NOBLE J. and PRENTICE S.: Adaptation to unilateral change in lower limb mechanical properties during human walking. Exp. Brain Res., 169 (4): 482-95, 2006.

25- OLNEY S.J., MACPHAIL H.A., HEDDEN D.M. and BOYCE W.F.: Work and power in hemiplegic cerebral palsy gait. Phys. Ther., 70 (7): 431-8, 1990. 
26- LAM T., ANDRESCHITZ M. and DIETZ V.: Contribution of feedback e feedforward strategies to locomotor adaptions. J. Neurophysiol., 95 (2): 76673, 2006.

27- SUSAN S., BECKERS A.D. and BUCK M.: In FNP in Practice: An Illustrated Guide, M.V. Heidelberg, Ed., pp. 80-9, Springer, Berlin, Germany, 2003.

28- YOUDAS J.W., AREND D.B., EXSTROM J.M., HELMUS T.J., ROZEBOOM J.D. and HOLLMAN J.H. "Comparison of muscle activation levels during arm abduction in the plane of the scapula vs. proprioceptive neuromuscular facilitation upper extremity patterns," The Journal of Strength \& Conditioning Research, Vol. 26, No. 4, pp. 1058-65, P.C, 2012.

29- MENINGRONI C.S. NAKADA, L. HATA, A. FUZARO C., JÚNIOR W.M. and ARAUJO J.E.: "Contralateral force irradiation for the activation of tibialis anterior muscle in carriers of Charcot-Marie-Tooth disease: Effect of PNF intervention program," Revista Brasileira de Fisioterapia, Vol. 13, No. 5, pp. 438-43, 2009.
30- SHARMA K.N.: Handbook of Proprioceptive Neuromuscular Facilitation: Basic Concepts and Techniques, Lambert, Saarbrücken, Germany, 2012.

31- PINK P.M.S.: "Contralateral effects of upper extremity proprioceptive neuromuscular facilitation patterns," Physical Therapy, Vol. 61, No. 8, pp. 1158-62, 1981.

32- KOFOTOLIS N., VRABAS I.S., VAMVAKOUDIS E., PAPANIKOLAOU A. and MANDROUKAS K.: "Proprioceptive neuromuscular facilitation training induced alterations in muscle fibre type and cross sectional area," British Journal of Sports Medicine, Vol. 39, No. 3, p. e11, 2005.

33- SHERRINGTON C.: The Integrative Action of the Nervous System, Yale University Press, New Haven, UK, 1947.

34- SIMÃO,CAMILA R., REGALADO R., SPANIOL, ANA PAULA, et al.: Immediate effects of a single treadmill session with additional ankle loading on gait in children with hemiparetic cerebral palsy. Neuro Rehabilitation, 44: 1-9. 10.3233/NRE-182516, 2019.

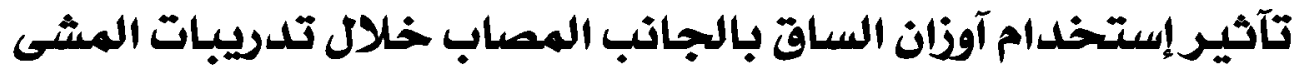 على قوة الضلات الرافعة للقدم فى حالات الوهن النان النصفى فى الآطفال}

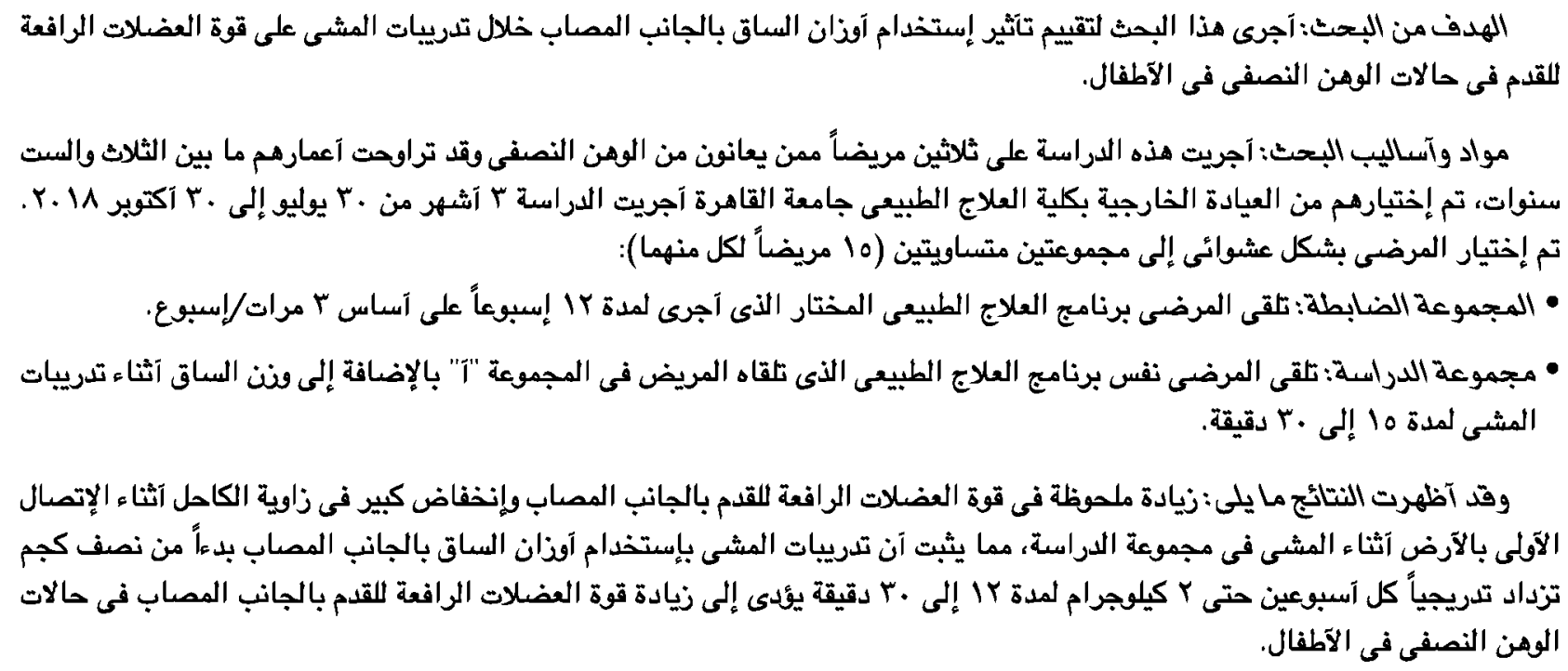

